\title{
ALI JE NARAVNA ČLENITEV PROSTORA LAHKO IZHODIŠČE ZA NAČRTOVANJE IN UREJANJE PROSTORA?
}

Janez Marušič

Biotehniška fakulteta, Oddelek za krajinsko arhitekturo, Jamnikarjeva I0I, SI-I000 Ljubljana

Izvirni znanstveni članek

COBISS 1.01

\section{Izvleček}

Prispevek obravnava različne členitve prostora $\mathrm{v}$ prostorskem načrtovanju in jih povezuje $\mathrm{z}$ načrtovalnimi postopki. Naravne členitve prostora naj bi bile značilne za načrtovanje rabe naravnih virov, kar je bila vsebina krajinskega načrtovanja v njegovih zgodnjih začetkih. Arbitrarno določane prostorske enote, katerih najbolj znan predstavnik so rastrske prostorske informacijske enote, pomenijo premostitev dveh povsem različnih 'geometrij' prostora.

Ključne besede: regija, regionalizacija, krajinska enota, prostorsko načrtovanje, okoljsko načrtovanje

\section{IS NATURAL REGIONALISATION OF LANDSCAPE A BASIC ELEMENT FOR SPATIAL PLANNING AND SPATIAL MANAGEMENT?}

\begin{abstract}
Regionalization as an activity that splits a landscape into units can be carried out differently according to the planning procedures used. The natural landscape units are connected to the planning of natural resource, which were the content of landscape at its very beginning. The arbitrary defined landscape units, i.e. raster pixels can be considered as a type of spatial unit that may surmount the two opposing types of landscape units.
\end{abstract}

Key words: region, regionalization, landscape unit, spatial planning, environmental planning 


\section{UVOD}

Proslava visokega jubileja akademika prof. Vrišerja je priložnost tudi za kakšno reminiscenco na njegovo delo. In ko sem se spraševal, o čem in kaj povedati, sem se ustavil na členitvah prostora, ki jim prof. Vrišer v svojem temeljnem delu Regionalno planiranje (1978) posveča celo 4. poglavje. Takoj moram poudariti, da je to 4. poglavje bilo zgolj vzpodbuda za razpravo, ki odpira drugačne probleme, kot jih je odpiral prof. Vrišer. Teza, ki jo tu postavljam, je, da je regija enota prostora in da je regionalizacija postopek oblikovanja takih prostorskih enot. Regionalizacija naj bi bila opravilo členjenja prostora na enote, ki je enako ne glede na njihovo velikost. Med splošneje razširjenim pojmovanjem regije in regionalizacije in kakršnimi koli drugimi členitvami prostora naj ne bi bilo bistvene razlike. In prav tako naj ne bi bilo razlike med regijo in kakršnokoli drugo prostorsko enoto v pogledu vloge, ki jo imata regija in neka druga kakršnakoli prostorska enota $\mathrm{v}$ postopku planiranja prostora. Take teze $\mathrm{v}$ resnici niso drugačne od definicij, ki jih podaja prof. Vrišer. Nenazadnje prof. Vrišer pravi, da je definicija regije ohlapna, in to pripisuje dejstvu, da pojem uporabljajo različne stroke 'in vsaka med njimi razume in tolmači ter uporablja ta termin drugače' (1978:132). Vendar naj bi regija pri prof. Vrišerju nakazovala prostorsko enoto večjih razsežnosti. Označevala naj bi določen teritorij, določeno pokrajino, tudi ozemlje, na katerem prebiva določena družbena skupnost. Tudi tipologija regij, ki jo prof. Vrišer predstavlja v nadaljevanju, kaže na to, da gre za prostorsko dokaj obsežna območja, ki pomenijo dejansko enoto nekega prostorskega plan ali razvojnega programa. Fiziognomične (naravne) regije, tehnične regije, historične, administrativne in statistične regije, ekonomske regije, homogene regije in funkcijske ali nodalne regije so vse opredeljene kot sorazmerno velike prostorske enote, katerih značilnost je, da jih opredeljuje neka skupna značilnost. Razprava v nadaljevanju se omejuje na prostorske enote manjšega, lahko bi rekli celo, da se razprava omejuje na enote najmanjšega obsega.

$\mathrm{V}$ bistvu določa prostorsko enoto njena notranja homogenost, bodisi notranja enakost značaja - fiziognomične, historične, tehnične, ali dejstvo skupne pripadnosti enoti nekega širšega sistema - administrativne, statistične in ekonomske, bodisi skupna notranja povezanost - nodalne in funkcijske. Prof. Vrišer tudi za sam postopek opredeljevanja takih enot, za regionalizacijo, pravi, da obstaja polno zamisli in različnih modelov, ki jih ni mogoče spraviti na skupni imenovalec. ‘Še več,' pravi prof. Vrišer, 'iluzorna je vsaka misel o tem, da bi pri sedanji razvojni stopnji znanstveno teoretične misli dobili nekakšne univerzalne planske regije, ki bi vsestransko ustrezale in ki bi imele idealno lastnost, da bi jih lahko uporabili za vse koncepte' (Vrišer, 1978:137). V nadaljevanju pa teče razprava predvsem o enotah prostora, ki so enote možne rabe prostora.

\section{NARAVNA ALI KRAJINSKA ENOTA}

V krajinskem planiranju se zamisel prostorske enote, ki bi bila hkrati enota neke planske opredelitve, na primer enote namenske rabe prostora, pojavi zelo zgodaj. B. Hacket (1971: 26-44) pozna naravno območje (angl. natural area) kot osnovno izhodišče za načrtovanje 
namenske rabe prostora. Nestor kanadskega krajinskega planiranja A. Hills (Lovejoy,1979:41) je razvil sistem členjenja krajinskih enot, od regij mnogovrstne rabe (angl. multiple use regions), preko krajinskih (angl. landscape unit) do zemljiških enot (angl. land unit). Tako členjene enote so bile A. Hillsu izhodišče za načrtovanje namenske rabe prostora, pri čemer je osnovna najmanjša 'zemljiška enota' hkrati najmanjša enota, v kakršne se prostor naravno členi, in najmanjša enota načrtovanja namembnosti prostora, torej enota, v kateri se določa ena sam raba zemljišča.

J. Lyle-u (1985: 53) so prostorske enote izhodišče za tipološko ločevanje postopkov krajinskega načrtovanja. Načrtovalske postopke, ki izhajajo iz vnaprejšnjega členjenja prostora, opredeljuje kot 'pristop s krajinsko enoto' (angl. landscape unit approach). Sam sicer krajinske enote imenuje upravljavske enote (angl. management zones). Tudi nekatera novejša dela s področja krajinskega načrtovanja izhajajo iz vnaprejšnjega členjenja prostora. A. Beer (1990:298) govori o enotah krajinskega značaja (angl. landscape character zone) in prav tako tudi P. Gilder(1993:46) v zvezi z oblikovanjem tako imenovanega 'Novega zemljevida Anglije'.

Vse omenjene enote imajo kar nekaj skupnih značilnosti:

- $\quad$ izhajajo iz stanja prostora - to je največkrat naravno stanje prostor ali pa so to značilnosti rabe zemljišč,

- $\quad$ so notranje homogene v pogledu neke značilnosti - posamezne, na primer talni tip, reliefne ali mezoklimatske značilnosti ali kompleksne značilnosti, kot so krajinski (videzni) značaj, ekosistemske značilnosti in podobno,

- $\quad$ so enkratne, kar pomeni, da se ločijo od sosednjih enot po stanju izbrane prostorske značilnosti (če bi sosednja enota bila enaka, potem ne bi bilo razloga za njeno razločevanje),

- jih je mogoče v prostoru zamejiti,

- $\quad \mathrm{z}$ njimi zapolnimo nek prostor načrtovanja $\mathrm{v}$ celoti in

- $\quad$ so lahko zelo različne po obsegu in obliki, ker sta tako obseg kot oblika odvisna od stanja prostora.

Zdi se, da sta za uporabo pristopov s krajinsko enoto pomembna dva vidika:

- c čas, ko se v krajinskem načrtovanju uveljavljajo in

- cilji ter nameni načrtovanja.

Kanadčan A. Hills in Anglež B. Hackett kot pomembna predstavnika takega pristopa sta bila dejavna v 60-tih in zgodnjih 70-tih letih prejšnjega stoletja. Sam J. Lyle predstavlja lastno načrtovalsko delo iz zgodnjih 70-tih let (1985: 55-68), ki ga uvršča med pristope s krajinsko enoto. Kasnejši primeri, ki jih navajata A. Beer in P. Gilder, ne označujejo neposredno načrtovalnih postopkov. Najbrž lahko sklenemo, da pristopi s krajinsko enoto označujejo zgodnjo dejavnost krajinskega planiranja v 60-tih in 70-tih letih 20. stoletja. Razlog za njihovo uveljavitev pa gotovo ni bil samo to, da so bili pač neka začetna tehnika krajinskega planiranja, temveč je na njihovo uporabo vplivala tudi vsebina takratnega krajinskega planiranja. $V$ tistem obdobju je bila vsebina izrazito povezana $\mathrm{z}$ načrtovanjem rabe naravnih virov in $\mathrm{z}$ varstvom narave. To značilno povezanost načrtovalnih postopkov s specifično vsebino krajinskih načrtov po svoje potrjuje tudi pojav drugačnih načrtovalnih postopkov. 


\section{TEHNIKE SIVIH TONOV}

J. Lyle (1985: 246) predstavlja te drugačne postopke krajinskega načrtovanja kot 'tehnike sivih tonov' (angl. graytone techniques). Gre za tehnike prekrivanja tematskih zemljevidov, kot jih je teoretično predstavil L. Hopkins v mnogokrat citiranem članku Methods for Generating Land Suitability Maps (1977) in ki so danes osnova računalniškim postopkom obdelave prostorskih podatkov. Če izvzamemo neko zelo zgodnjo uporabo metode prekrivanja prosojnih zemljevidov, o kateri poročajo C. Stenitz s sodelavci in ki naj bi se uporabila že davnega leta 1912 (1976), se ti pristopi začenjajo uveljavljati šele v 70-tih letih prejšnjega stoletja. Povezujejo jih z delom Iana McHarga (Lyle, 1985 246) in njegovimi kompozitnimi kartami. Čeprav je McHarg dejaven že v 60-tih letih, pa doživi 'tehnika sivih tonov' pravi razcvet v 70-tih in 80-tih letih prejšnjega stoletja. Njen prenos v računalniško podprte postopke, ki ga je trasiral Laboratorij za računalniško grafiko Harvardove univerze iz ZDA, na področju krajinskega planiranja še posebno C. Steinitz s sodelavci, je tehniki utrdil prevladujoč položaj v sodobnem prostorskem planiranju. Geografski informacijski sistemi so postali običajno planersko orodje.

Kaj je bil vzrok za ta spremenjen pristop k krajinskemu načrtovanju? Koncem 60-tih let, natančno decembra 1969, se pojavijo presoje vplivov na okolje kot načrtovalsko orodje za okoljevarstveno načrtovanje. Ian McHarg je bil pri zasnovi tega orodja zelo dejaven. Na predavanju, ki ga je imel v Ljubljani leta 1998 za študente krajinske arhitekture, je vzkliknil: «Presoje vplivov na okolje - orodje, ki sem ga iznašel jaz! « Ne glede na to, de je bila ta izjava morda pretirana, imamo I. McHarga lahko vsaj za soustvarjalca presoj vplivov na okolje. Predmet krajinskega načrtovanja načrtovanja niso več naravni viri oziroma dejavnosti, ki jih izkoriščajo, temveč druge dejavnosti: infrastruktura, poselitev, industrija, čeprav to pot v obrnjeni podobi: kje naj bi ne bilo teh dejavnosti zaradi zahtev varstva okolja in narave.

Krajinsko planiranje je od svojih začetkov pomenilo z naravo skladno načrtovanje. Vendar se je omejevalo na načrtovanje rabe naravnih virov. S pojavom krize v okolju se je aktivno vključilo na širše okoljevarstveno naravnano načrtovanje prostora. Dejavnosti, ki so bile predmet načrtovanja so bile vse razvojne dejavnosti. Ian McHarg se kot krajinski planer sprašuje, 'Kje naj potekajo ceste?' in odgovarja, da najboljša trasa ni tista, ki na najkrajši način povezuje dve točki, temveč trasa, ki daje največje družbene koristi ob najmanjših družbenih stroških (McHarg, 1969: 32). To kaže na očitno preusmeritev krajinskega planiranja na širše probleme okoljsko skladnega načrtovanja prostora. Kot krajinskemu in regionalnemu planerju mu razširitev načrtovanja krajine z okoljevarstvenim načrtovanjem celotnega prostora ni bila težka. S tem je tudi utemeljil okoljsko planiranje kot izhodišče za kakršnokoli načrtovanje prostora. Pristop s 'krajinskimi enotami' pa ni bil več uporaben za načrtovanje dejavnosti, kakršna je na primer avtocesta. Avtocesta je prostorski pojav, ki sledi posebnim zahtevam, ki jih v prostoru ni mogoče videti. Je ozek in dolg trak, ki povezuje dve ali več izhodiščnih točk. Meje tega traku nikakor niso določene z nekimi naravnimi značilnostmi, pač pa obliko in obseg ceste določajo značilnosti avtoceste kot grajenega objekta in njene prometne funkcije same. Prostorsko načrtovalna tehnika se je morala spremeniti. 


\section{ARBITRARNO DOLOČENE KRAJINSKE ENOTE}

Zanimivo je, da se je v tem času pojavila tehnika, ki bi jo lahko imeli za neke vrste prilagoditev 'pristopa s krajinsko enoto' na nove načrtovalne zahteve. Sistem zgodnjega opozarjanja, ki so ga pripravili T. Patri s sodelavci s Kalifornijske univerze v Berkely-u (Patri, Ingmire, 1972:219-249), je bil namenjen presojanju sprejemljivosti različnih dejavnosti v prostoru. Sistem se je opiral na členitev prostora $v$ prostorske enote. Toda te niso bile naravne enote, ki bi zamejevale neka po naravnih značilnostih notranje homogena območja. T. Patri s sodelavci so prostorske enote zasnovali kot enote, ki so bile vrisane $\mathrm{v}$ pravilno ortogonalno kartografsko mrežo. Ni bila pomembna notranja homogenost, temveč zgolj možnost, da take enote nosijo s sabo različne informacije o prostoru. Prednost tako zasnovanih enot je, da jim lahko pripišemo zelo različne informacije. Ker so prostorsko vedno enako opredeljene, omogočajo tudi postopke 'sivih tonov' ali McHargovih kompozitnih kart. Krajinske enote so s tem zelo očitno opredelili kot prostorske informacijske enote, kar nenazadnje je tudi vsaka druga kakorkoli že opredeljena prostorska enota. Tako zasnovane prostorske enote so kot nosilke informacij o prostoru enake rastrskim celica - pikslom pri rastrskem prikazovanju prostora. Ta pa je danes ena od dveh kartografskih tehnik prikazovanja prostora $v$ digitalnih medijih. Zanimivo je, da je domala istočasno, ko so raziskovalci s Kalifornijske univerze v Berkeley-u razvili zamisel Sistema zgodnjega opozarjanja, C. Steinitz s sodelavci v okviru Laboratorija za računalniško kartografijo Harvardove univerze razvijal podoben sistem, ki pa je izšel iz premišljanja o tem, kako za potrebe kartografije izrabiti računalniški tiskalnik. Tako so opravili primerjavo vrste krajinskoplanerskih metod tistega časa s pomočjo enega prvih rastrsko podprtih računalniških programov (Steinitz Rogers Ass., 1969).

Vključevanje okoljevarstvenih meril v prostorsko načrtovanje je pripeljalo do neskladja med pojavnostjo okoljskih kakovosti v prostoru, torej med 'geometrijo narave', in med obliko in obsegom človekovih dejavnosti v prostoru, 'geometrijo posegov'. Medtem ko se naravni pojavi kažejo v prostoru v zelo različnem obsegu in v zelo različni obliki in so zato tudi naravno členjene enote večinoma povsem nepredvidljivih oblik in velikosti, pa človekove dejavnosti in posegi $\mathrm{v}$ prostor sledijo njihovim velikostnim potrebam in funkcionalnim zahtevam. Ti dve 'geometriji', naravna in človekova, sovpadata samo pri tistih dejavnostih, pri katerih se potrebe in način delovanja prilagajajo naravnim razmeram in pri katerih je uspešnost človekovega delovanja v največji meri odvisna od naravnih razmer. To pa so dejavnosti, ki izrabljajo naravne vire: kmetijstvo, gozdarstvo, rekreacija, naravovarstvo in podobne. Dejavnosti, ki so bolj neodvisne od naravnih razmer, kot so infrastrukturni objektiti morajo vedno povezovati neke izhodiščne točke v prostoru, ne glede na naravne razmerein nasploh vse urbane dejavnosti se v prostoru širijo po pretežno lastnih zakonitostih in po lastni 'geometriji'. Toda zahteve za razvoj v prostoru, ki naj bi bil z okoljem skladen ali sonaraven, se vendarle nanašajo na prostorske kakovosti, katerih prostorska pojavnost sledi 'geometriji narave'. Tako se srečujemo dejansko s potrebo po hkratnem upoštevanju dveh oblik prostorske regionalizacije: ene, ki izhaja iz obstoječega prostora, in druge, ki izhaja iz bodoče ureditve prostora. 
Arbitrarno določene krajinske enote pomenijo dejansko možnost premostitve neskladja dveh prostorskih 'geometrij'. Prostorski raster ustvarja prostorske enote, ki lahko opisujejo različne prostorske oblike, tako naravne kot tiste, ki jih narekujejo človekovi posegi v prostor. Opisovanje oblik je zato bolj vprašanje natančnosti opisovanje, to pa vprašanje velikosti prostorskih enot. Bolj kot so prostorske enote majhne po obsegu, natančneje opisujejo pojavne oblike prostora. Tako si lahko take rastrsko določene prostorske enote predstavljamo kot podenote znotraj naravnih enot. Vsaka od njih nosi lahko informacijo o značaju take naravne enote, tudi o njeni okoljevarstveni ali naravovarstveni vrednosti. Taka enota se hkrati lahko prilagaja tudi človekovemu posegu kot prostorskemu pojavu, in sicer kot njegova prostorska podenota. Taka enota je povsem uporabna za soočanje človekovega posega $\mathrm{z}$ različnimi okoljevarstvenimi ali naravovarstvenimi zahtevami. Tako je tudi razumljivo, zakaj se rastrski sistemi digitalizacije prostorskih podatkov ohranjajo v različnih geografskih informacijskih sistemih, nekatera programska orodja, kot so na primer najbolj zahtevna iz družine ArcInfo, so jih celo kasneje uvedla, navkljub resnim kartografskim omejitvam, ki jih kažejo, na primer navkljub nenatančnemu prikazovanju prostora ali prevelikemu obremenjevanju spominskih zmogljivosti. Ne samo to. Večina današnjih geografskih informacijskih sistemov premore funkcije transformacij prostorskih entitet, to je točk, črt in ploskev, $v$ rastrski zapis in obratno.

\section{SKLEP}

Razprava o prostorskih enotah je bila vzpodbujena s spoznanjem, da se v slovenskem, predvsem, varstvenem načrtovanju pogostokrat pojavljajo pobude, ki nimajo ustrezne teoretične osnove. Tak najbolj očiten primer so bile v Zakonu o varstvu okolja (1993) in ponovno kasneje v Zakonu o ohranjanju narave (1999) določene ekosistemske enote, ki naj bi bile osnova za presojanje prostorskih načrtov. Informacija o ranljivosti prostora, ki naj bi bila prostorsko opredeljena v skladu s takimi enotami, pa za presojanje 'prostorske kakovosti' prostorskih načrtov ni bila uporabna. S 'prostorsko kakovostjo' je tu mišljena ustrezna lokacijska, tudi ustrezna oblikovna opredelitev posegov in dejavnosti v prostoru. Šlo je pač za neskladje med 'geometrijo narave', ki naj bi narekovala ekosistemsko členjenje, in med 'geometrijo' posegov in razvojnih dejavnosti, ki jo razkriva prostorski plan. Razumljivo je, zakaj se to zakonsko določilo ni uveljavilo in je bilo opuščeno ob prenovi zakona (Zakon o varstvu okolja, 2004).

Novejši primer so prav tako zakonsko uveljavljene različne kategorije zavarovanih območij opredeljene z zelo pomembnim poslanstvom. Bile naj bi osnova za izdajanje soglasja $\mathrm{k}$ različnim prostorskim razvojnim pobudam in planom. Celovita presoja vplivov na okolje, kot je danes zastavljena, naj bi se opirala na prostorske informacije, ki so izrazito vezane na 'geometrijo narave'. Območja Nature 2000, in kaže, da bo to danes v Sloveniji poglavitni parameter presojanja prostorskih planov (Pravilnik, 2004, Uredba, 2005), so zelo očiten primer prostorske informacije, ki je vezana na naravno pojavnost prostorskih kakovosti. Seveda tu ni problem naravne razmejitve nekih naravnih pojavov, čeprav bi o negotovosti zarisovanja prostorskih meja takih naravnih kakovosti tudi lahko razpravljali. Problem je transformacija prostorske informacije o kakovostih prostora $\mathrm{v}$ obliko, kakšno zahteva potreba po ustreznem 
presojanju posegov v prostor. $\mathrm{V}$ tem primeru pravzaprav ne pomaga veliko, če sicer vektorsko zabeležene informacije o naravnih območjih preoblikujemo v rastrski zapis. Problem tiči drugje.

Medtem ko je bila eksositemska enota mišljena kot prostorska nosilka informacije o večji ali manjši okoljevarstveni vrednosti prostora, pa je sedanji sistem območij posebnih režimov varovanja bolj kompleksna informacija, v kateri je skrita tudi že odločitev o ustrezni ali neustrezni rabi prostora. V pogledu soočanja različnih geometrij prostora je to še bolj neustrezna opredelitev, ker prostoru daje ureditveni vzorec, v katerem sploh ni bilo nikakršnega upoštevanja oblik načrtovanih posegov in dejavnosti.

Dejansko se razkrije, da pri današnjih slovenskih prizadevanjih za okoljsko prostorsko načrtovanje ni problem samo v teoretsko slabo podprtem 'geometriziranju' prostora, temveč je problem tudi nejasno razmejevanje med posameznimi koraki v prostorskem načrtovanju, predvsem razlikovanje med inventarizacijo, vrednotenjem in odločitvami o rabi prostora.

\section{Literatura}

Beer A.,1990. Environmental Planning for Site Development. E.\&F. N. Spon, London

Derek L.,1979. The Needss and Objectives of Landscape Planning. V: Land Use and Landscape Planning, Lovejoy D. ed., Leonard Hill, Glasgow

Gilder P., 1996. Novi zemljevid Anglije- Primer razvrščanja in ocenjevanja krajin. V: Tipološka klasifikacija krajine, mednarodni posvet. Urad RS za prostorsko planiranje, Ljubljana

Hopkins L.,1977. Methods for generating land suitability maps: a comparative evaluation. Journal of the American Institute of Planners 43(4): 386-400

Lyle J. T., 1985. Design for Human Ecosystems. Van Nostrand Reinhold Co., New York

Hackett, B., 1971. Landscape Planning. Oriel Press, Newcastel upon Tyne

Vrišer I., 1978. Regionalno planiranje. MK, Ljubljana

McHarg I., 1969. Design with Nature. The Natural History Press, Garden City, New York

Patri T., Ingmire T.J., 1972. Regional Planning and the Early Warning System. V: Krajinsko planiranje, Zbornik Simpozija,Katedra za krajinsko arhitekturo in vrtnarstvo, BF, UL, Ljubljana, 219-237

Pravilnik o presoji sprejemljivosti vplivov izvedbe planov in posegov v naravo na varovana območja, Uradni list RS 130/2004

Steinitz Rogers Ass., 1970. A General System for Environmantal Resources Analysis. The Public Land Law Review Commision, Washington

Seinitz C., Parke P., Jordan L., 1976. Hand drawn overlays:their history and prospective uses. V Landscape Architecture 9:444-455

Uredba o okoljskem poročilu, 2005. http//:www.sigov.si/mop/

Zakon o ohranjanju narave - ZON, Uradni list RS, št. 56/1999

Zakon o varstvu okolja - ZVO, Uradni list RS, št. 32/1993

Zakon o varstvu okolja - ZVI, Uradni list RS, št. 41/2004 


\title{
IS NATURAL REGIONALISATION OF LANDSCAPE A BASIC ELEMENT FOR SPATIAL PLANNING AND SPATIAL MANAGEMENT?
}

\begin{abstract}
Summary
Regionalization as an activity, which divides landscape into units can be realized differently according to the planning procedures used. The natural landscape units related to the planning of the natural resource represent a 'natural spatial geometry'. The development plan normally introduces another type of spatial articulation, i.e. 'human spatial geometry'. These two different spatial 'geometries' have become more important when the environmental impact assessments were brought into landscape planning. The need for some kind of a common articulation technique emerged. The arbitrarily defined landscape units, i.e. raster pixels, can be considered a type of spatial unit that may surmount the two opposing types of landscape units. The problem of differently defined landscape units has become more apparent in Slovenia after the legislation prescribed different assessment systems.

Discussion about spatial units was stimulated by the recognition, that in Slovene planning initiatives frequently appeared, which had no theoretical foundations. Such most obvious examples were determined ecosystem units, as basic element for assessment of spatial plans in Environmental protection Act and again later in Nature preservation Act (1999). Yet, the information about vulnerability which should be spatially determined in accordance with these units, were not applicable to assessment of »spatial quality«. The term »spatial quality« stands for the appropriation of location, and the appropriation of moulded determination of space intervention and activities. This, of course, caused discrepancy between "geometry of nature«, which dictated ecosystem division and between »geometry« of space intervention and development activities determined by the plan. It is understandable why these legislative determinations were not enforced and were abolished in renovation of the act (Environmental protection Act, 2004)

Recent examples are also enforced by legislation through different categories of protected areas, determined by the very important missions. They should be used as the basis for issuing concordance to different spatial development initiatives and plans. Comprehensive environmental impact assessment, as it is determined today, should draw on spatial information, which are strictly related to "geometry of nature«. Areas of Natura 2000, that are likely to become Slovenia's principal parameter for assessing spatial plans (Standing orders, 2004, Enactment, 2005), are very clear example of spatial information, which is related to the natural appearance of spatial quality. Clearly, we are not dealing here with the division of natural phenomena, although we might discuss the uncertainty of border determination of such natural qualities. The problem is in transformation of spatial information of space quality into a form, which would be most suitable for spatial intervention assessment. Since the problem lies elsewhere, it is not much of a help, if we transform vector information into raster record.

While the ecosystem unit was meant to be as an unit for spatial information about larger or smaller spatial environmental value, is today's system of areas of special protection regimes more complex information, information in which decision of suitable or non-suitable land use
\end{abstract}


is hidden. From the aspect of the confrontation of different spatial geometries this is an even more unsuitable determination, because it results in space arrangement pattern in which no forms of planning intervention were considered.

Actually it is reviled, that today's Slovenian efforts towards environmental spatial planning has no problem only in weak theoretical based »geometry of space« but in vague delimitation between different steps in spatial planning, above all delimitation between intervention, valuation and decisions about land use. 